\title{
STUDI RESPONS PUJIAN MAHASISWA ATAS PENCAPAIAN PRESTASI DALAM KELAS
}

\author{
Muhammad Husin Al Fatah ${ }^{1}$
}

\begin{abstract}
Abstrak
Di Indonesia, sering dihadapkan pada kesalahpahaman ketika siswa bahasa L2, dalam bahasa Inggris ini, memiliki komunikasi. Penelitian ini bertujuan untuk menganalisis tanggapan pujian yang digunakan oleh mahasiswa sarjana Jurusan Bahasa Inggris Universitas Negeri Semarang terhadap kinerja presentasi kelas dan kelancaran berbahasa Inggris mereka. Data dikumpulkan menggunakan pendekatan alami yang memungkinkan kuliah memberi mereka pujian setelah menyelesaikan presentasi mereka dalam bahasa Inggris. Data dianalisis menggunakan kerangka kerja Tran se (2007). Pujian diberikan dengan dua cara komunikasi, yakni menggunakan bahasa Inggris dan Bahasa Indonesia. Hasil yang diperoleh dalam hal pujian yang diberikan dalam bahasa Inggris adalah para siswa merespons menggunakan bahasa Inggris, tetapi tetap menggunakan perilaku komunikasi Bahasa Indonesia. Sementara itu, mahasiswa diberikan pujian dalam Bahasa Indonesia memiliki tanggapan yang berbeda. Dapat disimpulkan bahwa, mahasiswa dapat mentransfer perilaku bahasa dalam menanggapi pujian meskipun dalam beberapa aspek masih menggunakan perilaku Bahasa Indonesia sebagai L1 mereka ketika memiliki komunikasi dalam bahasa Inggris sebagai L2 mereka
\end{abstract}

Kata Kunci: Tanggapan Pujian, Prestasi, Bahasa Indonesia (L1) dan Bahasa Inggris (L2)

\begin{abstract}
In Indonesia, it is often faced misunderstanding when the students of L2 language, in this English, having communication. This study aims to analyse the compliment responses used by the undergraduate students of English Department of Semarang State University towards their performance of classroom presentation and their English speaking fluency. The data were collected using naturally approach which allowed the lecture gave them compliment after finishing their presentation in English. The data were analyzed using Tran"s framework (2007). The compliment given in two ways of communication, using English and Bahasa Indonesia. As the results, in term of compliment given in English, the students responded using English but still using Bahasa Indonesia communication behavior. Meanwhile they were given compliment in Bahasa Indonesia, they responded differently. It can be concluded that, they were able to transfer the behavior of language in responding compliment although in some aspects they still using Bahasa Indonesia behavior as their L1 when having communication in English as their L2
\end{abstract}

Keyword: Compliment Responses, Achievement, Indonesian (L1) and English (L2)

\footnotetext{
${ }^{1}$ Institut Agama Islam Negeri Surakarta, email: fatah1912abdullah@ gmail.com
} 


\section{Pendahuluan}

Di Indonesia, pembelajar bahasa Inggris sering menghadapi mispersepsi dan kesalahpahaman dalam transfer tata bahasa ibu L2 ke dalam tata bahasa L2 (Inggris) mereka. Mereka lupa bahwa aturan Bahasa Indonesia dan Bahasa Inggris memiliki perbedaan yang besar. Realitas ini juga terjadi pada mahasiswa Jurusan Bahasa Inggris sebagai pembelajar L2. Selama penelitian saya di Jurusan Bahasa Inggris Universitas Negeri Semarang, minimnya praktik berbicara menjadi penyebab error dalam melakukan komunikasi dalam bahasa inggris. Selain itu penggunaan tata dan nuansa Bahasa Indonesia sebagai bahasa ibu masih memengaruhi pola komunikasi dalam Bahasa Inggris.

Ada beberapa alasan mengapa memilih topik kajian. Pertama, masalah transfer pragmatis pemahaman lintas budaya masih menjadi topik diskusi populer saat ini di banyak negara yang menjadikan Bahasa Inggris sebagai bahasa kedua (EFL) terutama di Asia yang memiliki transfer budaya dan pragmatis yang signifikan. Bahasa Inggris sebagai bahasa sasaran pembelajar perlu diperhatikan dari segi perilaku, norma, dan nilai bahasa agar komunikasi yang terjadi tidak menimbulkan bias.

Bagi mahasiswa Indonesia, hal tersebut memberikan kontribusi yang signifikan bagi perkembangan sistem pembelajaran mereka. Sebagian pelajar Indonesia belum menyadari perbedaan perilaku, norma, dan nilai bahasa. Diharapkan dengan menerapkan penelitian ini pengembangan kesadaran perilaku bahasa mereka akan mendapatkan transfer yang baik antara bahasa pertama (L1) ke bahasa kedua (L2).

Alasan terakhir adalah topik tersebut memiliki kontribusi yang berharga bagi perkembangan bahasa khususnya implementasi ragam perilaku bahasa dan penggunaan pragmatis. Mengetahui dan menerapkan kompetensi transfer pragmatis akan membuat peserta didik semakin terbangun komunikasi dengan penutur asli bahasa Inggris, sehingga tidak terjadi gap informasi yang menimbulkan kesalahpahaman.

Salah satu perbedaan yang paling terlihat dalam merespon pujian. Kebiasaan orang Indonesia, ketika menerima pujian banyak danatar mereka merespon pujian dengan gaya menolak (denial), berbeda dengan kebudayaan dan model kebahasaan barat dalam hal ini inggris. Mereka memiiki beberapa respon untuk menunjukkan kesopanan dan respek kepada orang lain.

Beberapa kajian tentang gap pemahaman tentang pujian dan cara meresponnya dilakukan beberapa peneliti. Yuan (2001) sebagaimana dikutip dalam Tran (2007) menyatakan bahwa menaggapi (responding) pujian mengungkapkan aturan bahasa yang digunakan dalam suatu komunitas tuturan dan elemen penting dari perangkat pemeliharaan wajah. Lebih lanjut dia menjelaskan, mempelajari respon pujian dapat meningkatkan pemahaman kita tentang budaya masyarakat, nilai-nilai sosial, organisasi sosial, serta fungsi dan makna bahasa yang digunakan 
dalam suatu komunitas. Penjelasan lain dari Saito dan Beecken (1997) menjelaskan bahwa respon pujian merupakan minat yang besar untuk penelitian karena berbeda dari budaya ke budaya.

Pomerantz (1978) seperti yang dikutip dalam Jing \& Wang (2006) telah menjelaskan tanggapan pujian dari perspektif pragmatis, studi empiris telah dilakukan dan menunjukkan bahwa penutur bahasa yang berbeda dan ragam bahasa mengikuti pola yang berbeda ketika menanggapi pujian. Al Fatah (2015) melakukan studi tentang transfer pragmatic yang dilakukan oleh mahasiswa sarjana dan pascasarjana Universitas Negeri Semarang. Penelitian ini menggunakan naturalistic approach dalam pengambilan data. Kemudian, studi ini mencoba menganalisis perbedaan respon pujian antara mahasiswa sarjana dan pascasarjana dalam merespon pujian dan dianalisa apakah mereka melakukan transfer pragmatik dalam merespons pujian tersebut

Pujian adalah alat untuk menyatakan persetujuan, dan tujuan lain untuk menunjukkan bahwa Anda menyukai beberapa aspek dari penampilan, karya, prestasi orang lain, dll. Tillit dan Bruder (1985: 66) menyatakan bahwa pujian menyatakan persetujuan, dan tujuan utamanya adalah untuk menunjukkan bahwa Anda menyukai beberapa aspek dari penampilan, rasa memiliki, atau pekerjaan orang lain. Beberapa orang menggunakan pujian untuk "memuja" seseorang, atau menyanjung untuk meningkatkan niat baik. Oleh karena itu, pujian yang berlebihan mungkin tampak tidak tulus.

Studi ini mengkaji bagaimana mahasiswa jurusan bahasa Inggris $\mathrm{S}-1$ Universitas Negeri Semarang dalam menerima pujian atas pencapaian prestasi mereka. Prestasi disini adalah kinerja dan performa mereka saat melakukan presentasi menggunakan Bahasa Inggris menggunakan teori respon pujian Tran (2007) sebagai pisau bedah analisanya.

Berdasarkan kerangka kerja Herbert (1989) dan Pomerantz (1978) dalam menganalisis respons pujian dalam studinya, Tran (2007) menawarkan Continua of Compliment Responses Strategies. Kerangka kerja baru ini terdiri dari dua kontinu strategi respons pujian: kontinum strategi respons pujian dari penerimaan hingga strategi penolakan dan strategi penghindaran kontinum (Tran, 2007)

Alasan diberikan mengapa kerangka baru ini harus diusulkan. Pertama, penelitian sebelumnya tentang respon pujian telah menyarankan berbagai kerangka kategori respon pujian seperti Herbert (1989), Pomerantz (1978), Al Khatib (2001), Gajaseni (1994), Golato (2002), Saito dan Beckend (1997). Tak satu pun dari kerangka kategori ini yang dapat dianalisis. Ia melakukan penelitian di Australia dan Vietnam. Kedua, studinya menunjukkan bahwa strategi respons pujian tidak terpisah tetapi terhubung satu sama lain dan membentuk sebuah kontinum. 
Volume 1, No 2, Desember 2020

Kategori Respon Pujian menurut Tran (2007)

\begin{tabular}{|c|c|c|}
\hline No & Types of Responses & Example \\
\hline \multirow[t]{12}{*}{1.} & Acceptance to Denial Continuum & A: Nice car \\
\hline & Compliment downgrade & B: Thanks, brand new \\
\hline & Agreement & $\begin{array}{l}\text { A: I like your car, It's good } \\
\text { B: Oh yeah thanks, It's not bad }\end{array}$ \\
\hline & Agreement token & $\begin{array}{l}\text { A: It's really stylisy } \\
\text { B: Yeah }\end{array}$ \\
\hline & Appreciation token & $\begin{array}{l}\text { A: What a lovely dress! } \\
\text { B: Oh thank you. }\end{array}$ \\
\hline & Return & $\begin{array}{l}\text { A: You're looking good today. } \\
\text { B: thanks, so are you. }\end{array}$ \\
\hline & Comment history & $\begin{array}{l}\text { A: I like your tie. } \\
\text { B: Thanks, my mom brought it for } \\
\text { me. }\end{array}$ \\
\hline & Reassignment & $\begin{array}{l}\text { A: You look nice today. } \\
\text { B: Thanks, it must be the jacket }\end{array}$ \\
\hline & Non idiomatic responses & $\begin{array}{l}\text { A: I like your car. } \\
\text { B: uh yes, (Nothing special) }\end{array}$ \\
\hline & Compliment downgrade & $\begin{array}{l}\text { A: It's nice car. I really like it. } \\
B: \text { Well, it's just a normal and not } \\
\text { very reliable car. }\end{array}$ \\
\hline & Disagreement & $\begin{array}{l}\text { A: Hey, I like your tie. It suits you } \\
\text { very well. } \\
\text { B: I don't think o }\end{array}$ \\
\hline & Disagreement token & $\begin{array}{l}\text { A: You'r looking so well } \\
\text { B: Uhm, no }\end{array}$ \\
\hline \multirow[t]{4}{*}{2.} & $\begin{array}{l}\text { The avoidance continuum } \\
\text { Expressing gladness }\end{array}$ & $\begin{array}{l}\text { A: I read the article you published } \\
\text { last week, it was very good. } \\
B: \text { Well, great. }\end{array}$ \\
\hline & Follow up question & $\begin{array}{l}\text { A: You know, I just read your } \\
\text { article las week. I thought it was } \\
\text { excellent. } \\
\text { B: Thanks a lot, what do you find } \\
\text { interesting with? }\end{array}$ \\
\hline & Doubting & $\begin{array}{l}\text { A: You are looking very nice } \\
\text { tonight. } \\
\text { B: Really? }\end{array}$ \\
\hline & Opting out & $\begin{array}{l}\text { A: Your car is very luxurious. } \\
\text { B: hehehe. }\end{array}$ \\
\hline
\end{tabular}




\section{Metode}

Penelitian ini merupakan studi kualitatif yang menganalisis tanggapan siswa Jurusan Bahasa Inggris terhadap pujian yang diberikan kepada mereka secara umum. Denzin dan Lincoln (2000) sebagaimana dikutip Ospina (2004: 2) menjelaskan bahwa penelitian kualitatif melibatkan pendekatan interpretif dan naturalistik. Artinya, peneliti data kualitatif mempelajari hal-hal dalam suasana alam, mencoba memahami, atau menafsirkan fenomena dalam istilah makna yang dibawa orang kepadanya.

Berkaitan dengan penelitian ini dijelaskan gambaran, analisis, dan interpretasi terhadap realisasi respon pujian mahasiswa Jurusan Bahasa Inggris Universitas Negeri Semarang. Deskripsi dihasilkan dengan menginterpretasikan proses penelitian tentang apa saja strategi tanggapan pujian yang dihasilkan oleh siswa baik Bahasa Inggris maupun Bahasa Inggris, perbedaan strategi di antara mereka, dan bagaimana strategi kesantunan mengganggu tanggapan pujian yang digunakan.

Tran (2007) membuat kategorisasi tanggapan pujian menjadi dua kategorisasi strategi utama. Yang pertama adalah menerima (acceptance continuum) dan yang kedua penolakan (avoidance continuum). Acceptance Continuum diturunkan menjadi 11 (sebelas) kategori, yaitu compliment upgrade (meningkat), agreement (setuju), agreement token (persetujuan singkat), appreciation token (apresisasi singkat), return (dikembalikan), explanation (penjelasan), reassignment (dialihkan), non-idiomatic responses (respon non bahasa), compliment downgrade (menurunkan), disagreement (ungkapan tidak setuju), disagreement token (ungkapan tidak setuju singkat).

Sedangkan Avoidance Continuum diturunkan menjadi empat kategorisasi yakni expressing gladness (ekspresi kegembiraan), follow up question (pertanyaan tindak lanjut), doubting (meragukan), dan opting out strategies (keluar strategi). Berdasarkan kategorisasi tersebut maka strategi respon yang diterapkan oleh mahasiswa. Meskipun demikian terdapat beberapa respon yang tidak sesuai dengan kerangka kerja Tran. Mereka dimasukkan ke dalam kategorisasi "lainnya". Strategi ini muncul karena perilaku bahasa pertama (L1) yang dialihkan ke bahasa kedua (L2) dalam hal ini bahasa Inggris sebagai komunikasi akademik sehari-hari.

Realisasi respon pujian disampaikan dengan cara yang berbeda oleh mahasiswa. Mereka menanggapi secara berbeda berdasarkan jenis pujian, jenis kelamin, situasi yang diberikan, dan tingkat pembelajaran. Para mahasiswa sarjana menerapkan strategi respon yang berbeda dari mahasiswa pascasarjana. Selain itu, jenis pujian dan bahasa baik L1 maupun L2 yang digunakan juga berkontribusi dalam menghasilkan perbedaan strategi respon pujian. Jenis pujian yang diterapkan di sini adalah pujian atas penampilan / kemampuan mahasiswa saat melakukan presentasi di dalam kelas. 
Volume 1, No 2, Desember 2020

Respons pujian berdasarkan strategi pujian yang diberikan

Pada studi ini diberikan sebuah situasi dan pujian kepada mahasiswa berdasarkan kinerja atau kemampuannya menggunakan Bahasa Inggris. Strategi pujian yang pertama adalah gambaran tentang pujian atas penampilan presentasi mereka, dan strategi pujian yang kedua adalah gambaran bagaimana siswa fasih berbahasa Inggris.

Strategi pujian 1

"what an amazing presentation, you must prepare it well."

$R:$

Respons:

\begin{tabular}{|c|c|c|c|}
\hline \multirow[t]{3}{*}{ Types of responses } & \multicolumn{3}{|l|}{ Compliment responses } \\
\hline & \multicolumn{2}{|l|}{ Undergraduate students } & \multirow[t]{2}{*}{ frek } \\
\hline & Female & Male & \\
\hline Appreciation token & $\begin{array}{l}\varnothing \text { Thanks } \\
\varnothing \text { Thank you } \\
\varnothing \text { Thanks }\end{array}$ & $\begin{array}{l}\text { Ø Thank you } \\
\varnothing \text { Thanks } \\
\varnothing \text { I appreciate it } \\
\varnothing \text { Thank you }\end{array}$ & 7 \\
\hline \multicolumn{4}{|l|}{ Return } \\
\hline Explanation & $\begin{array}{l}\text { Ø Thank you. I have done } \\
\text { a very hard work }\end{array}$ & $\begin{array}{l}\text { Ø Thanks dude, I've prepared } \\
\text { it } \\
\varnothing \text { Yes, I've prepared it } \\
\varnothing \text { Of course, I've prepared } \\
\text { before } \\
\emptyset \text { Thank you. I've prepared it } \\
\text { within this week }\end{array}$ & 5 \\
\hline $\begin{array}{l}\text { Compliment } \\
\text { downgrade }\end{array}$ & $\begin{array}{l}\varnothing \text { Thanks, but I don't feel } \\
\text { really satisfied } \\
\varnothing \text { I prepared it just a night } \\
\varnothing \quad \text { Thank you, I'm } \\
\text { nerveous }\end{array}$ & $\varnothing$ Not really & 6 \\
\hline
\end{tabular}




\begin{tabular}{|c|c|c|c|}
\hline & $\begin{array}{l}\varnothing \text { Thanks, but I just made } \\
\text { it last night }\end{array}$ & & \\
\hline Disagreement & $\begin{array}{l}\varnothing \text { I don't think that it's } \\
\text { good }\end{array}$ & & 1 \\
\hline Disagreement token & & & \\
\hline Expressing gladness & & $\varnothing$ My pleasure & 1 \\
\hline Doubting & Ø Really? Thank you & & 1 \\
\hline
\end{tabular}

Pada strategi pujian 1, respon pujian yang diberikan adalah appreciation token, explanation, compliment downgrade, disagreement, expressing gladness dan doubting question.. Appreciation token merupakan respons yang paling sering diterapkan dalam situasi ini dengan jumlah siswa 7 diikuti dengan explanation, compliment downgrade dan disagreement. Masing-masing berjumlah 5 siswa.

\section{Strategi pujian 2}

"Amazing, your English is so fluent, native alike."

$R:$

Respons:

\begin{tabular}{|l|l|l|l|}
\hline \multirow{4}{*}{ Types of responses } & \multicolumn{2}{|l|}{ Compliment responses } & \multirow{2}{|l|}{ frek } \\
\cline { 2 - 4 } & Undergraduate students & \\
\cline { 2 - 4 } & Female & Male & $\mathbf{3}$ \\
\hline Appreciation token & $\square$ Thank you & $\square$ Thank you & \\
& & $\square$ Thank you & \\
\hline Return & & You shouldn't say that. & $\mathbf{2}$ \\
\cline { 2 - 3 } & & &
\end{tabular}


Volume 1, No 2, Desember 2020

\begin{tabular}{|c|c|c|c|}
\hline & & $\begin{array}{l}\text { You're good too } \\
\square \text { Thanks, you're doing good } \\
\text { too }\end{array}$ & \\
\hline Explanation & $\begin{array}{l}\text { Thank you, I always } \\
\text { practice my pronunciation } \\
\text { by watching youtube } \\
\square \text { Thank you, it needs a lot } \\
\text { of practice }\end{array}$ & $\begin{array}{l}\square \text { Thank you. I always study } \\
\text { hard }\end{array}$ & 3 \\
\hline Reassignment & & & \\
\hline $\begin{array}{l}\text { Compliment } \\
\text { downgrade }\end{array}$ & $\begin{array}{l}\square \quad \text { Not really, I have just } \\
\text { mastered the topic } \\
\square \text { Thank you, I'm not that } \\
\text { smart. } \\
\square \text { Everyone can make it }\end{array}$ & $\begin{array}{l}\square \text { No thanks, I have a lot of } \\
\text { practice } \\
\square \text { Thanks, I'm not that fluent } \\
\square \quad \text { Haha, stop it. You're } \\
\text { embarrassing me }\end{array}$ & 6 \\
\hline Disagreement & $\begin{array}{l}\square \text { Not really } \\
\square \text { No, Not really }\end{array}$ & & 2 \\
\hline Disagreement token & & & \\
\hline Expressing gladness & & & \\
\hline Follow up question & & & \\
\hline Doubting & $\begin{array}{l}\square \text { Really? No, I only got B } \\
\text { score } \\
\square \text { Really, thanks a lot }\end{array}$ & $\begin{array}{l}\square \text { Oh really? } \\
\square \text { Really? Thanks }\end{array}$ & 4 \\
\hline
\end{tabular}


Respons serupa tampak pada strategi pujian ke 2 yang diberikan. Respons yang diterapkan disini sebagian besar sama dengan strateg pujian ke 1. Mereka adalah appreciation token, return, explanation, compliment downgrade, disagreement, dan doubting question. Satu-satunya perbedaan yang muncul adalah respon yang paling sering diterapkan. Penurunan peringkat pujian adalah yang paling sering diterapkan di sini. Berbeda dengan strategi pujian ke 1 yang menempatkan appreciation token sebagai respons yang paling sering diterapkan.

Respon pujian berdasarkan bahasa yang digunakan

$$
\text { Selain siswa telah memahami }
$$
perbedaan respon yang diterapkan berdasarkan jenis pujian yang diberikan, mereka juga menggunakan respon yang berbeda saat pujian diberikan dalam bentuk Bahasa Indonesia. Beberapa dari mereka merespon pujian tersebut secara berbeda dan beberapa dari mereka merespon dengan menggunakan strategi yang sama baik versi Inggris maupun Indonesia

Strategi Pujian 3

Pujian: "Keren, presentasimu luar biasa, pasti persiapannya mantap."

$R$

\begin{tabular}{|l|l|l|l|}
\hline \multirow{4}{*}{ Types of responses } & \multicolumn{2}{|l|}{ Compliment responses } & frek \\
\cline { 2 - 4 } & \multicolumn{2}{|l|}{ Undergraduate students } & \multicolumn{2}{|l|}{ Male } & $\mathbf{1 0}$ \\
\cline { 2 - 4 } & Female & $\square$ Makasih & \\
\hline Appreciation token & $\square$ Makasih & $\square$ Terimakasih & \\
& $\square$ Makasih & $\square$ Terimakasih & \\
& $\square$ Terimakasih & $\square$ Terimakasih banyaK & \\
\hline Return & $\square$ Makih & $\mathbf{2}$ \\
\hline Explanation & $\square$ Kamu juga bagus & $\square$ Terimakasih, kamu juga & \\
\hline Reassignment & $\square$ Persiapannya lama. & & \\
\hline
\end{tabular}


Volume 1, No 2, Desember 2020

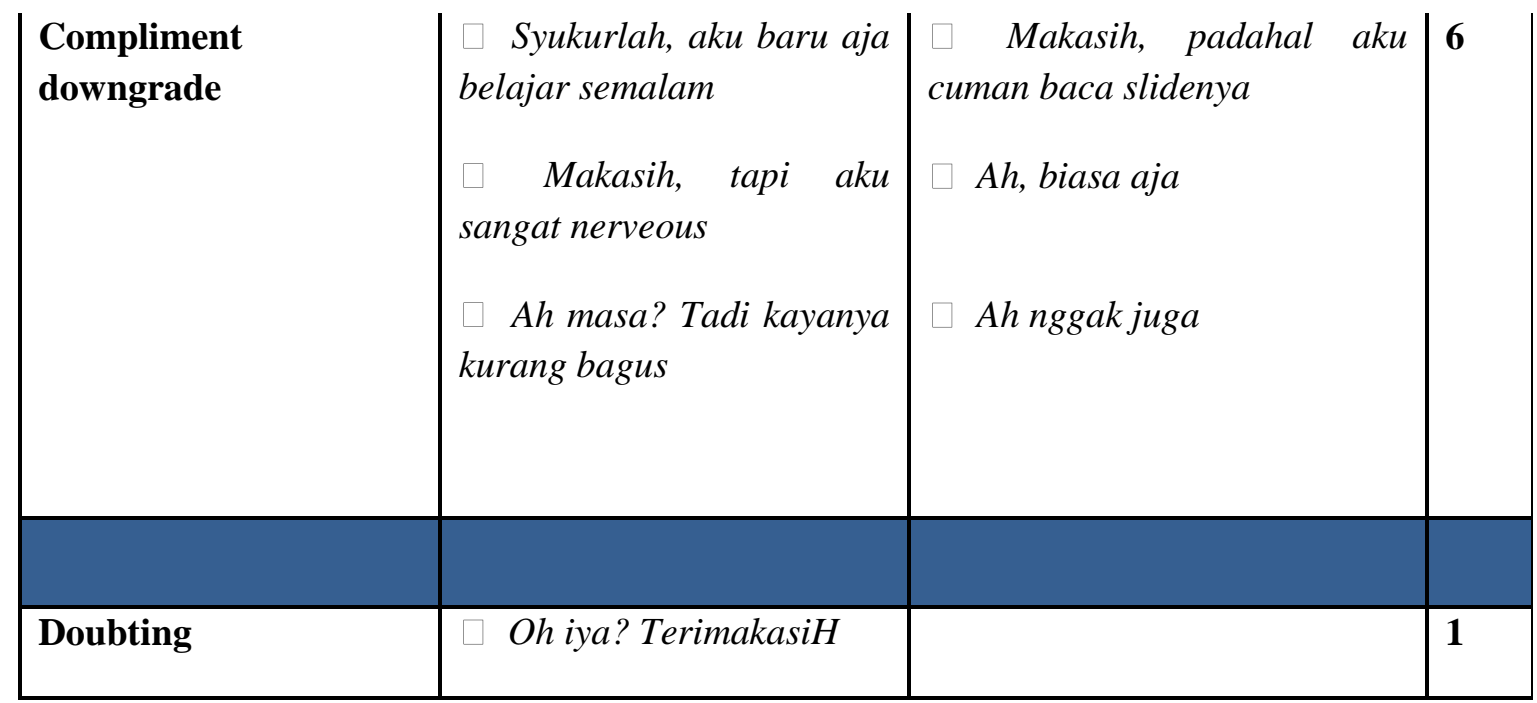

Pada strategi pujian ini baik versi bahasa Inggris maupun bahasa Indonesia mahasiswa menerapkan strategi serupa seperti appreciation token, explanation, dan compliment doowngrade. Appreciation token versi bahasa Inggris berjumlah 7 mahasiswa, explanation 5 mahasiswa, compliment downgrade 5 siswa. Sedangkan versi bahasa Indonesia, appreciation token 3 mahasiswa, return 1 mahasiswa, explanation 4 siswa, dan compliment downgrade 3 mahasiswa. Dalam versi bahasa Inggris, appreciation token menjadi respon yang paling sering diterapkan.

Respons pujian yang tidak Nampak dalam pujian berbahasa Inggris tetapi muncul dalam pujian versi bahasa Indonesia adalah agreement, dan doubting question. Agreement merupakan respon yang paling sering diterapkan dalam versi bahasa Indonesia. Di sisi lain, beberapa jenis respon yang tidak muncul dalam versi bahasa Indonesia namun muncul dalam versi bahasa Inggris adalah disagreement, expressing gladness, dan doubting.

Strategi Pujian 4

Pujian :"Mantap, bahasa inggrismu, mirip native speaker aja."

$R \quad$ :

\begin{tabular}{|l|l|l|l|}
\hline Types of responses & \multicolumn{2}{|l|}{ Compliment responses } & \multirow{2}{|l|}{ Frek } \\
\cline { 2 - 3 } & Undergraduate students & \\
\cline { 2 - 4 } & Female & Male & $\mathbf{1}$ \\
\hline Agreement & & & \\
& & & Ya dong, kan anak B3 \\
\end{tabular}


Volume 1, No 2, Desember 2020

\begin{tabular}{|c|c|c|c|}
\hline Appreciation token & & $\begin{array}{l}\square \text { Makasih ya } \\
\square \text { Makasih pujiannya } \\
\square \text { Iya makasih } \\
\square \text { Terimakasih } \\
\square \text { Makasih } \\
\square \text { Terimakasih }\end{array}$ & 6 \\
\hline Return & $\begin{array}{l}\text { Masih bagusan kamu } \\
\text { lah, aku cuman lewat } \\
\text { youtube belajarnya }\end{array}$ & & 1 \\
\hline Explanation & $\square$ Hehe, latian tiap hari & & 1 \\
\hline Reassignment & & & \\
\hline $\begin{array}{l}\text { Compliment } \\
\text { downgrade }\end{array}$ & $\begin{array}{l}\square \quad \text { Hehe, empot-empotan } \\
\text { nih } \\
\square \quad \text { Oh ya? Padahal cuman } \\
\text { dapat Nilai B } \\
\quad \text { Makasih, tapi nggak } \\
\text { keren juga kok, cuman } \\
\text { paham topic aja sih. } \\
\square \text { Makasih, nggak pinter } 2 \\
\text { amat kok } \\
\square \text { Aku masih belajar hehe } \\
\square \text { Ah, nggak juga }\end{array}$ & $\begin{array}{l}\square \text { Haha, udah deh, jadi malu } \\
\square \text { Haha, nggak kok, cuman } \\
\text { latian aja terus }\end{array}$ & $\overline{8}$ \\
\hline Doubting & $\square$ Ah masa? & $\begin{array}{l}\square \text { Masa sih? } \\
\text { Masa? Haha makasih }\end{array}$ & 3 \\
\hline
\end{tabular}

Pada startegi pujian ke-4 ini, respon yang diberikan baik versi bahasa Inggris maupun bahasa Indonesia memilki kesamaan yakni explanation, compliment downgrade, dan doubting question. Jenis respons explanation versi bahasa Inggris berjumlah 3 
siswa, dan dalam versi bahasa Indonesia hanya 1 siswa. Kemudian, compliment downgrade versi bahasa Inggris adalah 8 siswa, jenis respons ini yang paling sering digunakan

Hasil lainnya adalah respon pujian yang tidak muncul dalam versi bahasa Inggris adalah agreement, apresiasi token, dan return. Sementara itu, dalam versi Indonesia, jenis respon yang tidak muncul adalah adalah agreement token dan disagreement strategy.

Berdasarkan analisis kategori jenis respon pujian Tran (2007), dapat disimpulkan bahwa mahasiswa telah memberikan jenis-jenis respon yang sesuai dengan teori respon pujian Tran. Tanggapan pujian itu diterapkan dalam dua bahasa, Inggris dan Indonesia. Meskipun mereka menyampaikan respon pujian dalam dua cara bahasa, namun perilaku bahasa Indonesia dalam istilah transfer pragmatis adalah bahasa pertama (L1), berperan penting. dalam mengembangkan komunikasi pemahaman bahasa Inggris sebagai bahasa ke dua (L2).

Dalam menanggapi pujian yang diberikan, mahasiswa sebagai pembelajar bahasa asing mencerminkan perilaku bahasa pertama (L1) mereka sampai batas tertentu. Sebagai siswa English as Foreign Language (EFL), mereka mentransfer perilaku bahasa L1 mereka dalam hal ini Bahasa Indonesia ke bahasa L2 dalam hal ini Bahasa Inggris baik transfer negatif maupun positif. Dalam beberapa realisasi respon pujian, mereka juga mentransfer perilaku bahasa L2 ke L1 mereka. Mereka mengembangkan L2 dan menggabungkan perilaku bahasa L1 mereka dengan L2.

\section{Kesimpulan}

Perbedaan respons yang digunakan dalam penelitian ini dipengaruhi oleh kesadaran pragmatis mahasiswa yang memiliki latar belakang budaya perilaku berbahasa Indonesia. Dalam menanggapi pujian tersebut khususnya dalam bahasa Inggris, mereka telah mengalihkan perilaku bahasa Indonesia ke dalam bahasa Inggris. Transfer semacam ini menimbulkan kesalahpahaman dan keraguan bagi penutur asli Bahasa Inggris. Dalam studi ini, transfer pragmatis ditemukan dalam beberapa strategi respons. Ekspresi yang digunakan seperti "don't mention it" dan "stop, you're overated", bagi orang Indonesia kalimat ini biasa digunakan untuk merendahkan pujian, tetapi bagi penutur asli bahasa Inggris membuat mereka agak bingung. Ungkapan "I buy it in Klithikan," untuk menanggapi pujian memiliki dan "No Thanks, I have a lot of practices" untuk menanggapi pujian kemampuan menunjukkan kesadaran budaya telah mempengaruhi siswa. Bagi masyarakat Indonesia khususnya masyarakat Jawa, ungkapan seperti ini biasa digunakan untuk merendahkan pujian. Artinya benda-benda yang dimiliki hanyalah benda biasa sehingga tidak layak untuk dipuji. Kemudian ungkapan "Tidak makasih, saya banyak latihan" memiliki arti bahwa ia membutuhkan banyak latihan untuk melakukan kegiatan semacam itu, jadi tidak ada gunanya dipuji. 


\section{Daftar Pustaka}

Al Fatah, MH. (2015). "Pragmatic Transfer in Compliment Response Strategies of The English Department Students of State University of Semarang." English Education Journal, 5(1).

Cai, Ying. (2012). "A Study on Compliment Responses Strategies by Chinese College Students." Journal of Language Teaching and Research, Vol.3, No.3, pp 543-549.

Chen, Shu-hui Eileen. (2003). "Compliment Response Strategies in Mandarin Chinese: Politeness Phenomenon Revisited." Concentric: Studies in English Literature and Linguistics, Vol.29, No.2, pp157-184

Furko, Balint Peter \& Eva Dudas. (2011). "Gender Differences in Complimenting Strategies with Special Reference to the Compliment Response Patterns of Hungarian Undergraduate Students." Journal of Argumentum, Vol.8, pp.136-157

Han, Chung hye. (1991). A Comparative Study of Compliment Responses: Korean females in Korean interactions and in English interactions. WPEL: Working Papers in Edeucational Linguistics, Vol.8, No.2. pp 14-31.
Jing, Qu \& Li, Wang. (2005). Pragmatic Transfer in Compliment Responses by Chinese Learners of English. Paper Presented at AARE Annual.

Tillit, B and Bruder,M.N. (1985). Speaking Naturally. Cambridge: Cambridge University Press.

Tran, Gioo Quyn. (2003).The Naturalized Role-play: An innovative methofology in cross-cultural and interlanguage pragmatics research, Melbourne: Reflection on English Language Teaching, Vol,. 5, No. 2, pp 1-24

Tran, Gioo Quyn. (2007). Compliment Responses Continuum Hypothesis, Melbourne: The International Journal of Laguage Society and Culture, www.educ.utas.edu.au/users/tle/JOUR NAL. Online. [Accessed April 23 ${ }^{\text {th }}$ 2014]

Tran, Giao Quyn. (2010). Replying to Compliments in English and Viatnemese. Melbourne: The International Journal of Laguage Society and Culture.Vol 30, No.1, pp 104-109

Ospina, Sonia. (2004). Qualitative Research. London: SAGE Publication. 